\title{
HACIA EL SISTEMA NACIONAL DE TRANSPARENCIA
}

\section{Uriel Eugenio GONZÁLEZ ESPINOSA*}

El texto Hacia el sistema nacional de transparencia es un trabajo coordinado por Jacqueline Peschard que reúne una serie de artículos de destacados académicos que buscan exponer desde diferentes aristas las ventajas y los retos que supone a las instituciones públicas del país y a la sociedad civil en general la adopción de la reforma constitucional en materia de transparencia y acceso a la información pública, publicada en el Diario Oficial de la Federación (DOF) el 7 de febrero de 2014. Esta reforma establece los cimientos que dan origen al llamado sistema nacional de transparencia.

La envergadura del tema conlleva a plantearse una serie de interrogantes sobre la capacidad de los sujetos obligados para procesar el escrutinio de una ciudadanía cada vez más ávida de información y de participar activamente en el proceso de toma de decisiones. Uno de los principales retos, por lo tanto, será crear los mecanismos institucionales que le otorguen valor estratégico a la información pública para convertirla en una herramienta de los ciudadanos que permita evaluar las decisiones de los actores encargados de tomar las decisiones.

Con esto en cuenta, hay que destacar que el texto coordinado por Jacqueline Peschard se divide en tres capítulos. En el primero, titulado "La problemática de la expansión del derecho de acceso a la información”, tanto Sergio López-Ayllón como la propia Jacqueline Peschard reconocen que el derecho de acceso a la información pública es producto de un amplio proceso de apertura política que tiene origen en la reforma constitucional de

* Licenciado en ciencias políticas y administración pública por la Facultad de Ciencias Políticas y Sociales de la UNAM, ure.gospinoza@gmail.com. 
1977, considerada como la piedra angular del proceso de democratización de nuestro régimen político. Asimismo, estos autores reconocen que desde la década de los setenta se ha impulsado un cambio institucional que ha dado prioridad al establecimiento de una serie de derechos políticos y civiles en la sociedad mexicana, mismos de los que forma parte el derecho de acceso a la información pública. Para decirlo con más claridad, después de la reforma constitucional de 1977 el cambio institucional se acentuó en el afianzamiento de elecciones libres y competitivas. Una vez que se institucionalizó la competencia electoral por la vía democrática, se reconoció la necesidad de abrir los procesos de gobierno al escrutinio de la sociedad mediante el derecho de acceso a la información.

Sin embargo, tal como lo identifican Óscar Guerra y Emilio Giménez en su texto, los avances que en la materia se han obtenido a nivel federal, permeados por una legislación de avanzada, se encontraron regularmente con trabas y obstáculos en los niveles de gobierno estatal y municipal, de tal modo que los avances que supuso en el ámbito federal la expedición de la Ley Federal de Transparencia y Acceso a la Información Pública Gubernamental (2002), así como sus posteriores reformas, para salvaguardar el derecho de acceso a la información, quedaron suprimidos en el ámbito local de gobierno. La interpretación del referido derecho a nivel local se realizaba a través de las leyes estatales y los reglamentos en la materia, que en múltiples ocasiones iban en contrasentido con la Ley Federal. Esta situación dio un giro con la reforma constitucional de 2014, dado que ésta afianza tanto la coordinación entre los tres órdenes de gobierno como el carácter vinculatorio de la norma, con la finalidad de que el órgano garante se sobreponga a las reticencias de las autoridades locales para ser escrutadas por los ciudadanos.

El capítulo dos lleva por título "Los retos del nuevo sistema nacional de transparencia”, y se construye desde dos ópticas. En primera instancia, Cecilia Azuara y Pedro Salazar identifican con gran detalle los cambios legales que se han implementado dentro de nuestro sistema político en materia de transparencia y acceso a la información desde 2002 al hacer un recuento somero de los avances en la materia. Ambos reconocen, desde dos puntos de vista diferentes, que la reforma de 2014 contribuyó de manera notable al fortalecimiento del órgano garante de acceso a la información al dotarlo de autonomía política, técnica y de gestión, y al elevar a rango constitucional el carácter definitivo e inatacable de sus resoluciones.

Por otra parte, el artículo de Eduardo Bohórquez se muestra más propositivo, al señalar que la reforma de 2014 abre la oportunidad de utilizar la información pública de manera estratégica, con la intención de combatir 
la corrupción, abatir la desconfianza social y dotar a los ciudadanos de una herramienta que les permita alcanzar un Estado de derecho. El principal reto de esta reforma no radica en promover la aplicación de la ley para que los derechos se cumplan, sino en lograr que las instituciones funcionen adecuadamente, lo cual quiere decir que la "infoestructura" que la norma contempla para expandir el derecho de acceso a la información a todo el territorio nacional de nada servirá si las instituciones públicas y la sociedad no otorgan un uso estratégico a la información gubernamental, y si el derecho no contribuye a la innovación y a la solución de las necesidades de los ciudadanos.

En otro tenor se encuentra el texto presentando en conjunto por Mauricio Merino, Veloz Márquez y Hernández Colorado, que plantea la necesidad de construir un sistema de rendición de cuentas que tome como base la publicidad de la información y la transparencia — derechos que garantiza la reforma constitucional de 2014- En primera instancia, estos autores hacen una disertación sobre la importancia de la rendición de cuentas en un sistema de gobierno democrático, dando cuenta que éste no puede florecer sin la existencia del primero. La rendición de cuentas cobra sentido una vez que el gobierno ha sido electo a través de las urnas; por lo tanto, la rendición de cuentas — de acuerdo con estos autoresconserva una condición bifronte; por una parte, es una herramienta ciudadana para monitorear las acciones del gobierno y, a su vez, permite al gobierno acercase a los ciudadanos para resolver de manera más adecuada sus necesidades.

Asimismo, estos autores presentan una propuesta conceptual-metodológica sobre la rendición de cuentas, que considera a ésta como una cadena cuyos eslabones son en sí mismos condiciones para un buen gobierno. La cadena estaría compuesta por siete eslabones: 1) archivos, 2) información pública, 3) contabilidad, 4) presupuesto, 5) compras públicas, 6) monitoreo y evaluación, y 7) fiscalización, lo cual constituye un conjunto de controles que permiten disminuir la discrecionalidad en el ejercicio de los recursos públicos y del poder político.

Finalmente, en el capítulo tres, titulado "Los alcances de la transparencia en los nuevos sujetos obligados", se plantean los retos y los obstáculos que deberán enfrentar algunos de los nuevos sujetos obligados (los partidos políticos, las universidades públicas, el Congreso de la Unión y los órganos constitucionales autónomos, entre los que se cuenta al propio órgano garante de transparencia) para dar plena certeza al cumplimiento de la reforma de 2014. 
Al respecto, Luis Emilio Giménez Cacho estudia de manera detallada las complejidades de la adopción de la transparencia partidista en nuestro sistema político, dada la reticencia de algunos actores políticos para brindar información sobre la vida institucional de sus agrupaciones. Tal como reconoce el autor, desde la década de los noventa la transparencia partidista se encuentra ampliamente ligada al cambio institucional experimentado en la arena electoral, dado que en los ordenamientos legales en la materia (incluido el Cofipe) se le otorgaba al entonces Instituto Federal Electoral (IFE) la potestad de auscultar no sólo el gasto de los partidos, sino su vida interna, fungiendo como intermediario entre la ciudadanía y los partidos en materia de derecho de acceso a la información pública. Esto contribuyó de manera importante a cimentar estructuras interpartidistas que funcionan como verdaderas unidades de transparencia - aunque no en todos los casos- Sin embargo, la reforma de 2014 abre un nuevo ciclo en la vida institucional de los partidos políticos en México, dado que la autoridad electoral deja de ser un intermediario y se obliga a los partidos a otorgar de forma directa la información que les sea solicitada.

Por otra parte, Ángel Trinidad Zaldívar discute sobre los retrasos que las universidades públicas del país enfrentan para garantizar el derecho de acceso a la información, debido a que en múltiples casos la autonomía constitucional de que gozan ha servido para forjar la idea de extraterritorialidad, lo que supone creer que las universidades públicas autónomas no se encuentran obligadas a dar cumplimiento a las garantías constitucionales. Desde el punto de vista del autor, esta situación resulta paradójica, pues son las universidades públicas las que deberían mantener la batuta para educar y concientizar a la sociedad civil en esta materia predicando con el ejemplo.

En el texto escrito por Khemvirg Puente, al hablar del Congreso mexicano, se reconoce que la opacidad y la falta de rendición de cuentas por parte de nuestros legisladores se debe en gran medida a que la organización interna de éste descansa en la concentración de poderes y recursos en los partidos parlamentarios. Asimismo, argumenta que la normatividad interna admite que los grupos parlamentarios y sus coordinadores gasten sin justificar o comprobar el ejercicio de los recursos que les son asignados. Por lo tanto, un elemento fundamental de la reforma constitucional de 2014 es que el Congreso es considerado como sujeto obligado, lo cual le obliga a documentar todas sus actividades, tomando en cuenta el principio de máxima publicidad. Así, el principal reto para garantizar el acceso a la información en todas las funciones y responsabilidades a cargo del Congreso radica en la infraestructura institucional que se logre consolidar para dar 
cumplimiento a la norma, ya que la capacidad técnica de los órganos y el compromiso político de los responsables tienen un papel relevante para la consecución de los objetivos de la norma.

En este mismo capítulo, Marván Laborde aborda un tema no menos importante, referente a los efectos que traerá la adopción de la reforma constitucional de transparencia en los organismos constitucionales autónomos (OCA). En primera instancia, plantea una discusión teórica sobre el papel que detentan los OCA en el diseño institucional de la división de poderes. Posteriormente, expone de manera detallada cómo evolucionó el principio de transparencia y acceso a la información pública en los OCA, haciendo hincapié en que todos siguieron un modelo en el que un órgano garante interno resolvía sobre las peticiones de información pública, con la posibilidad (en la mayoría de los casos) de que sus resoluciones pudieran ser revisadas por un segundo órgano (que se integraba regularmente por uno o más de los miembros que formaban parte del órgano garante interno). Esta situación se modifica con la reforma constitucional de 2014, ya que los OCA también quedarán sujetos a la autoridad del órgano garante de transparencia, e incluso este propio órgano garante deberá cumplir una doble función de sujeto obligado y juez.

En suma, el libro Hacia el sistema nacional de transparencia tiene la gran ventaja de ser un documento de reflexión y análisis en un momento crucial de la vida institucional mexicana, aun cuando el Congreso continúa discutiendo la legislación secundaria que dará plena vigencia al sistema nacional de transparencia a fin de consolidar los avances de la reforma constitucional. Además, la notoriedad del libro radica en que no se trata de un documento dirigido a estudiantes e investigadores, pues cualquier interesado en la materia podría adentrarse en su lectura, siempre que busque conocer los avances, los logros y los retos de nuestro sistema político en esta materia.

Sin embargo, uno de los aspectos que juega en contra de este estudio - y de cualquier estudio de análisis de coyuntura - es la rapidez con la que la realidad política evoluciona. Tras la reforma constitucional de 2014, vino la aprobación de la Ley General de Transparencia y Acceso a la Información Pública (publicada en el DOF el 4 de mayo de 2015), que entre sus principales aspectos se encuentran: 1) definir la estructura, atribuciones y objetivo del sistema nacional de transparencia; 2) señalar con claridad las obligaciones de transparencia a que deben someterse los sujetos obligados, y 3) delinear los principios de la política nacional de transparencia, la cual busca articular la labor del órgano garante nacional y de los 32 órganos garantes locales. 
Los esfuerzos que se han implementado en esta materia en el ámbito legislativo deben ser reconocidos por su innovación y compromiso con la defensa del derecho de acceso a la información, pero — tal como algunos de los autores arriba referenciados reconocen- la principal dificultad para garantizar el derecho de acceso a la información pública no radica en tener una legislación de avanzada, sino en crear los instrumentos institucionales que permitan su aplicación. Al parecer, el órgano garante nacional, denominado por la Ley General como Instituto Nacional de Transparencia, Acceso a la Información y Protección de Datos Personales (INAI), cuenta con las herramientas necesarias para convertirse en una - institución fuerte y con credibilidad; sin embargo, conseguirlo depende de

- las decisiones que adopten los propios comisionados; ahí el reto.

\section{Bibliografía del Libro RESEÑAdo}

Peschard, Jacqueline (coord.), 2016, Hacia el sistema nacional de transparencia, México, UNAM, Instituto de Investigaciones JurídicasSeminario Universitario de Transparencia. 